
\title{
$\begin{array}{ll}\text { Research Square } & \begin{array}{l}\text { Preprints are preliminary reports that have not undergone peer review. } \\ \text { They should not be considered conclusive, used to inform clinical practice, } \\ \text { or referenced by the media as validated information. }\end{array}\end{array}$
}

\section{Three-dimensional CT Angiography Facilitates Uniportal Thoracoscopic Anatomic Lung Resection for Pulmonary Sequestration}

\author{
Wenlong Zheng \\ Xuzhou Medical University \\ Miao Zhang \\ Xuzhou Central Hospital \\ Wenbin Wu \\ Xuzhou Central Hospital \\ Hui Zhang \\ Xuzhou Central Hospital \\ Zhang Xinhui ( $\sim$ zhangxhdoc@hotmail.com) \\ Xuzhou Central Hospital https://orcid.org/0000-0002-4356-6042
}

\section{Research article}

Keywords: Bronchopulmonary sequestration (BPS), pulmonary sequestration (PS), video-assisted thoracoscopic surgery (VATS), three-dimensional computed tomography angiography (3D-CTA)

Posted Date: October 28th, 2021

DOI: https://doi.org/10.21203/rs.3.rs-1001707/v1

License: (c) (1) This work is licensed under a Creative Commons Attribution 4.0 International License. Read Full License 


\section{Abstract}

Background

Pulmonary sequestration (PS) is a rare lesion with independent blood supply from an anomalous systemic artery. A timely resection is considered the best treatment for PS, but the optimal approach is controversial. Three-dimensional computed tomography angiography (3D-CTA) has been widely utilized for precise thoracic surgery. This study aimed to investigate the safety of uniportal video-assisted thoracoscopic surgery (VATS) for PS assisted with preoperative 3D-CTA.

Methods

The data of patents with PS who underwent VATS anatomic lung resection between April 2011 and May 2021 in a single centre were retrospectively reviewed. They were divided into uniportal and tow-port groups according to the initial surgical plan. The perioperative parameters including the incidence of conversion to open thoracotomy, operation time, blood loss, complications and chest tube duration were analyzed.

Results

Twenty consecutive patients ( 9 in uniportal group and 11 in two-port group) underwent VATS for PS, including 12 female and 8 male patients, with a mean age of 45 years old (range, 24-60 years). Nine cases demonstrated recurrent febrile, cough, or hemoptysis; whereas the other 11 patients were asymptomatic. The 3D-CTA was utilized for all patients in the uniportal group and 1 patient in the two-port group. Eighteen ( $90.0 \%)$ intralobar and 2 extralobar PS were confirmed; and $18(90.0 \%)$ lesions were located in the left thorax. The feeding vessels originated from the thoracic aorta in 16 patients ( $80.0 \%)$, the abdominal aorta in $3(15.0 \%)$ and the inferior phrenic artery in 1 patient (5.0\%). Thirteen lobectomies, 5 segmentectomies and 2 mass excisions were performed. There was no major bleeding or 30-day mortality. No conversion was needed in the uniportal group; whereas 6 (54.5\%) conversions (4 to multiple-port and 2 to thoracotomy) occurred in the two-port group, indicating a significant difference $(\mathrm{P}=0.008)$. In addition, the operation time in the uniportal VATS group was significantly shorter than those in the two-port VATS group $([110.6 \pm 25.5] \mathrm{min}$ vs. $[148.6 \pm 42.1] \mathrm{min}, \mathrm{P}=0.029)$. The other perioperative variables were similar between the two groups. During the follow-up of 5-75 months, no recurrence of hemoptysis was recorded.

Conclusion

Preoperative 3D-CTA facilitates the safe performance of uniportal VATS anatomic lung resection for PS, which might be associated with shorter operation time and lower conversion to thoracotomy.

\section{Background}

Pulmonary sequestration (PS) is classified into intralobar sequestration (ILS) and extralobar sequestration (ELS), with a non-functioning abnormal lung tissue receiving arterial supply by one or more systemic vessels. Multi-detector computed tomography (CT) plays a key role in the diagnosis of PS and surgical planning. PS has a variety of appearances in CT images including consolidation, mass, or air/fluid-filled cystic or multicystic lesion [1]. Once a PS is diagnosed, resection is suggested, regardless of the symptoms. Lobectomy or segmentectomy by video-assisted thoracoscopic surgery (VATS) is the generally utilized surgical approach for PS.

Preoperative identification of the aberrant feeding (effluent and influent) vessels is critical to facilitate the safe performance of PS resection. Threedimensional CT angiography (3D-CTA) images were utilized to definitely identify the aberrant feeding arteries with/without accompanied drainage veins of the PS. In 2015, Lin et al. reported the first case of uniportal VATS lobectomy for intralobar PS in semiprone position [2]. This study aimed to summarize the experience of uniportal VATS anatomic resection of the sequestrated lung assisted with 3D-CTA and to evaluate the mid-term outcomes.

\section{Patients And Methods}

\section{Patients}

We retrospectively reviewed the perioperative data of 20 consecutive patients with PS who underwent VATS anatomic lung resection in Xuzhou Central Hospital between April 2011 and May 2021. They were categorized into uniportal and two-port VATS groups, with 9 and 11 patients in each group. Baseline demographics (age, gender, body mass index, pulmonary lung function), the characteristics of the PS (location, subtype, origin of aberrant artery), and perioperative variables (operation time, estimated blood loss, complications, and duration of chest drainage) were recorded (Table 1). There were 12 females (60.0\%), and the mean age of the patients was 45 years (range, 23-60 years). There were $18(90.0 \%)$ ILS and 2 (10.0\%) ELS patients. In addition, 2 (10.0\%) PS were located in the right lower lobe and 18 (90.0\%) were in the left thorax. Meanwhile, $16(80.0 \%), 3(15.0 \%)$ and 1 (5.0\%) PS showed aberrant feeding vessels originated from the thoracic aorta, abdominal aorta, and inferior phrenic artery, respectively. Of the 20 patients, the major symptoms were recurrent cough, expectoration or fever (5 cases, $25.0 \%$ ), and hemoptysis (4 case, $20.0 \%$ ); whereas the other 11 (55.5\%) patients were asymptomatic (Table 1 ). Patients with respiratory symptoms were controlled using antibiotics for the safety of surgery. All the patients revealed a single aberrant feeding artery, and they demonstrated normal cardiopulmonary function before surgery. Previous chest surgery, and estimated dense pleural adhesions as shown in the CT images were not contraindications of uniportal VATS. Actually, intent-to-treat protocol was used in this retrospective cohort study. 
Table 1

Baseline characteristics of the patients with pulmonary sequestration

\begin{tabular}{|c|c|c|c|c|}
\hline Variables & Total $(n=20)$ & Uniportal VATS $(n=9)$ & Two-port VATS $(n=11)$ & $P$ value \\
\hline Age, y & $45.0 \pm 9.1$ & $43.4 \pm 11.4$ & $46.2 \pm 6.8$ & 0.291 \\
\hline Female, $\mathrm{n}$ & $12(100 \%)$ & $6(66.7 \%)$ & $6(54.5 \%)$ & 0.582 \\
\hline Body mass index, $\mathrm{kg} / \mathrm{m}^{2}$ & $24.6 \pm 3.0$ & $25.8 \pm 2.8$ & $23.6 \pm 2.8$ & 0.119 \\
\hline Major symptoms on admission, $\mathrm{n}$ & & & & $0.049^{*}$ \\
\hline Recurrent respiratory tract infection (cough/expectoration/fever) & $5(25.0 \%)$ & $4(44.4 \%)$ & $1(9.1 \%)$ & \\
\hline Hemoptysis & $4(20.0 \%)$ & $3(33.3 \%)$ & $1(9.1 \%)$ & \\
\hline Asymptomatic & $11(55.0 \%)$ & $2(22.2 \%)$ & $9(81.8 \%)$ & \\
\hline Sequestration type, $\mathrm{n}$ & & & & 0.178 \\
\hline Intralobar & $18(90.0 \%)$ & $9(100.0 \%)$ & $9(81.8 \%)$ & \\
\hline Extralobar & $2(10.0 \%)$ & 0 & $2(18.2 \%)$ & \\
\hline Location of the sequestrated lung, $n$ & & & & 0.882 \\
\hline Left lower lobe & $18(90.0 \%)$ & $8(88.9 \%)$ & $10(90.9 \%)$ & \\
\hline Right lower lobe & $2(10.0 \%)$ & $1(11.1 \%)$ & $1(9.1 \%)$ & \\
\hline Origin of the aberrant feeding vessels, $n$ & & & & 0.497 \\
\hline Thoracic aorta & $16(80.0 \%)$ & $7(77.8 \%)$ & $9(81.8 \%)$ & \\
\hline Abdominal aorta & $3(15.0 \%)$ & $2(22.2 \%)$ & $1(9.1 \%)$ & \\
\hline Inferior phrenic artery & $1(5.0 \%)$ & 0 & $1(9.1 \%)$ & \\
\hline Venous drainage of the sequestrated lung, $n$ & & & & 0.582 \\
\hline Pulmonary veins & $8(40.0 \%)$ & $3(33.3 \%)$ & $5(45.5 \%)$ & \\
\hline Undetermined & $12(60.0 \%)$ & $6(66.7 \%)$ & $6(54.5 \%)$ & \\
\hline Preoperative FEV1, L & $3.0 \pm 0.5$ & $2.9 \pm 0.5$ & $3.1 \pm 0.5$ & 0.586 \\
\hline
\end{tabular}

\section{Preoperative 3D-CTA for resection simulation}

Initially, the PS was diagnosed by thin-slice two-dimensional CT images, and the experience of the radiologist and the surgeon play a critical role in correct diagnosis. Since the introduction of 3D-reconstruction technique in our hospital, the patients in this cohort established 3D-CTA by the free software, OsiriX (Apple Inc., California) using contrast-enhanced thin-slice CT sections (1.0 mm thickness) of the thorax and upper abdomen. The CTA images could definitely identify the diameter, length, and the course of the aberrant feeding vessels for surgical resection simulation.

\section{Surgical technique}

All patients were operated on under general anesthesia with selective one-lung ventilation using a double-lumen endotracheal tube.

For uniportal VATS, only an approximately $3.0-4.5 \mathrm{~cm}$ single incision was made at the $5^{\text {th }}$ intercostal space of the anterior axillary line with a wound protector (Johnson, New Brunswick, NJ, USA), without rib-spreading. A 30-degree, $10 \mathrm{~mm}$ thoracoscope (Karl Storz, Tuttlingen, Germany) was utilized for vision. Anatomic lobectomy, segmentectomy or mass resection of the sequestrated lung was performed for ILS and ELS respectively, using the standard uniportal technique as reported [3]. First, the aberrant feeding vessels were meticulously ligated using a non-absorbable silk suture or clipped with 1-2 Hemo-o-Lock vascular clips (Weck Surgical Instruments, Teleflex Medical, Durham, NC); whereas the linear staplers Endo-GIA (Medtronic Inc., Shanghai, China) were used for the vessels with a diameter of larger than $6 \mathrm{~mm}$ after suture ligation to reduce the risk of bleeding [4]. Next, the anatomic lung resection was performed after the division of the feeding vessels. The lobar or segmental vein, artery and bronchus were divided gradually. Each specimen was placed in a sterilized storage bag and pulled out. One $20 \mathrm{~F}$ chest tube was placed for pleural drainage.

For two-port VATS, an additional port was created along the $7^{\text {th }}$ intercostal space at the midaxillary line while the working port was placed in the $4^{\text {th }}$ or $5^{\text {th }}$ intercostal space along the anterior axillary line.

In addition, the enhanced recovery after lung surgery protocol was utilized individually in this cohort. Early removal of the urine tube allowed patients to mobilize freely, which was helpful to diminish the risk of atelectasis and deep venous thrombosis. The drainage tube was removed when the drainage amount decreased to $200 \mathrm{~mL}$ per day without air leak or obvious residual pneumothorax as shown in the chest X-ray. Patients were usually discharged the day after removal of the chest tube.

\section{Statistical analysis}


The continuous variables were presented as means \pm standard deviations and the categorical variables were presented as numbers and frequencies (\%). Differences between uniportal and two-port VATS groups were determined using analysis of variance (ANOVA) for continuous variables and Fisher's exact test for categorical variables. A P value of less than 0.05 was considered a significant difference. The data were analyzed using IBM SPSS Statistics for Windows, version 19.0 (IBM Corp., Armonk, NY, USA).

\section{Results}

The first 10 patients in the two-port group were diagnosed as PS using thin-slice two-dimensional CT images before the introduction of 3D-reconstruction software. Preoperative 3D-CTA digital anatomy models were established in the following 10 patients (1 in two-port group and 9 in the uniportal group), which revealed definitely the abnormal blood vessels. Most of the anomalous vessels could be identified around the lower pulmonary ligament.

Thirteen lobectomies and 5 segmentectomies were performed for ILS; whereas 2 mass resections were carried out for ELS. The perioperative features were shown in Table 2. There was no emergency reoperation or major bleeding in this cohort. Six conversions included 4 to multi-port VATS and 2 to thoracotomy were recorded in the two-port group, and the conversion incidence was obviously higher than that of the uniportal group (6 [54.3\%] vs. 0, P=0.008). In addition, the operation time in the uniportal VATS group was significantly shorter than those in the two-port VATS group ([110.6 \pm 25.5$]$ min vs. [148.6 \pm 42.1$]$ min, $\mathrm{P}=0.029)$. However, the estimated blood loss ([83.3 \pm 43.3$] \mathrm{mL}$ vs. [100.0 \pm 38.7$] \mathrm{mL})$, pleural drainage duration $([6.8 \pm 3.0] \mathrm{d}$ vs. [7.2 \pm 3.3$] \mathrm{d})$, and postoperative hospital stay $([8.0 \pm 3.5] \mathrm{d}$ vs. $[9.6 \pm 4.2] \mathrm{d})$ were similar between uniportal and two-port groups $(P>0.05$, respectively) .

Table 2

Perioperative clinical data of the patients

\begin{tabular}{|c|c|c|c|c|}
\hline Variables & Total $(n=20)$ & Uniportal VATS $(n=9)$ & Two-port VATS $(n=11)$ & P value \\
\hline Preoperative 3D-CTA and resection simulation, $n$ & $10(50.0 \%)$ & $9(100 \%)$ & $1(9.1 \%)$ & $<0.001^{*}$ \\
\hline Extensive pleural adhesion, $\mathrm{n}$ & $5(25.0 \%)$ & $3(33.3 \%)$ & $2(18.2 \%)$ & 0.436 \\
\hline Surgical procedures, $\mathrm{n}$ & & & & 0.178 \\
\hline Lobectomy or segmentectomy & $18(90.0 \%)$ & $9(100 \%)$ & $9(81.8 \%)$ & \\
\hline Mass resection & $2(10.0 \%)$ & 0 & $2(18.2 \%)$ & \\
\hline Conversion of the surgical approach, $n$ & $6(30.0 \%)$ & 0 & $6(54.5 \%)$ & $0.008^{*}$ \\
\hline Three-port VATS & $4(20.0 \%)$ & 0 & $4(36.4 \%)$ & \\
\hline Thoracotomy & $2(10.0 \%)$ & 0 & $2(18.2 \%)$ & \\
\hline Disconnection of aberrant vessels, $n$ & & & & 0.660 \\
\hline Endo-stapler & $17(85.0 \%)$ & $8(88.9 \%)$ & $9(81.8 \%)$ & \\
\hline Ligation using silk & $3(15.0 \%)$ & $1(11.1 \%)$ & $2(18.2 \%)$ & \\
\hline Mean operation time (range), min & $131.5 \pm 39.8$ & $110.6 \pm 25.5$ & $148.6 \pm 42.1$ & $0.029 *$ \\
\hline Estimated blood loss (range), $\mathrm{mL}$ & $92.5 \pm 40.6$ & $83.3 \pm 43.3$ & $100.0 \pm 38.7$ & 0.376 \\
\hline Postoperative complications, $\mathrm{n}$ & $4(20.0 \%)$ & $1(11.1 \%)$ & $3(27.3 \%)$ & 0.369 \\
\hline Pulmonary infection & $1(5.0 \%)$ & 0 & $1(9.1 \%)$ & \\
\hline Prolonged air leakage ( $>5$ days) & $1(5.0 \%)$ & $1(11.1 \%)$ & 0 & \\
\hline Chylothorax & $1(5.0 \%)$ & 0 & $1(9.1 \%)$ & \\
\hline Bronchopleural fistula & $1(5.0 \%)$ & 0 & $1(9.1 \%)$ & \\
\hline Mean duration of chest tube (range), $d$ & $7.3 \pm 3.1$ & $6.8 \pm 3.0$ & $7.2 \pm 3.3$ & 0.510 \\
\hline Postoperative hospital stay (range), d & $8.9 \pm 3.9$ & $8.0 \pm 3.5$ & $9.6 \pm 4.2$ & 0.362 \\
\hline Pathological diagnosis, $\mathrm{n}$ & & & & 0.257 \\
\hline PS & $19(95.0 \%)$ & $8(88.9 \%)$ & $11(100 \%)$ & \\
\hline PS combined with carcinoma & $1(5.0 \%)$ & $1(11.1 \%)$ & 0 & \\
\hline 30-day mortality & 0 & 0 & 0 & - \\
\hline Follow up, month & $35.3 \pm 19.0$ & $27.6 \pm 14.5$ & $41.6 \pm 20.4$ & 0.099 \\
\hline Recurrence of cough or hemoptysis & 0 & 0 & 0 & - \\
\hline
\end{tabular}

The postoperative course was mainly uneventful. The uniportal VATS group reported a (11.1\%) case of air leak; whereas the two-port group showed 3 (27.3\%) cases of complications (chylothorax, bronchopleural fistula, and pulmonary infection), without statistical difference between the two groups ( $P=0.396)$. All the 
complications were cured after conservative therapies. All the patients were discharged home in good condition after the removal of chest tubes.

Pathological and immunohistochemical staining of the resected lung tissues confirmed the diagnosis of PS; whereas one specimen revealed neuroendocrine carcinoma arising within the PS. During the median follow-up of 35.3 months (range, 5-75 months), no patients presented a recurrence of hemoptysis or dyspnea.

\section{Discussion}

The present retrospective cohort study confirmed the obvious superiority and safety of uniportal VATS anatomic lobectomy and segmentectomy assisted with preoperative 3D-CTA. Preoperative confirmation of the aberrant vessels significantly facilitates the operation, although it is not indispensable because careful dissection is mostly sufficient. There are several issued should be clarified.

To date, no established guidelines have been produced for PS treatment. Endovascular occlusion of the feeding artery probably leads to the necrosis, fibrosis and progressive involution of the sequestrated lung and therefore to minimize the risk of intraoperative bleeding. Thus, embolization plus surgical resection might be the optimal approach for complex cases with multiple or large feeding vessels. In addition, the time of surgery for PS is still controversial. An early resection of the sequestrated lung during childhood may prevent the subsequent respiratory symptoms and to prevent the rare and debated risk of transformation into malignancy [5].

A substantial number of lung anomalies present incidental or recurrent respiratory infections progressing into adulthood. Encountering these lung anomalies in adults is a diagnostic challenge and they are often mistaken and followed by unnecessary procedures [6]. For ILS patients, the venous drainage is into the pulmonary vein. Approximately two-thirds of ILS lesions are found in the posterior basal segment of the left lower lobe; whereas PS associated with Scimitar syndrome (partial anomalous pulmonary venous connection) is more common in right thorax [7]. For ELS patients, the venous drainage is into the systemic veins including the lower lobe vein, azygos vein, hemiazygos vein, subclavian or portal vein; whereas the arterial supply is from descending thoracic aorta (73\%), the cranial portion of the abdominal aorta, celiac trunk, splenic artery (21\%), intercostal arteries, pericardiophrenic, right coronary artery, subclavian, and internal thoracic arteries; meanwhile, the ELS are often found between the diaphragm and the lower lobes [7]. Additionally, the aberrant feeding artery into the PS may be more than one. Furthermore, the blood pressure of the aberrant arteries, which are often accompanied by inflammation and adhesion around the vessel, is sometimes high in PS patients. Moreover, PS should be distinguished from anomalous systemic arterial supply to the lung, because they both showed independent aberrant artery but the treatment aim and procedures are different. The differential diagnosis is essential to avoid fatal postoperative complications [8].

Therefore, the major challenge during operation for PS is the identification of the aberrant vessels. Two-dimensional multidetector CT image is somewhat insufficient to provide a comprehensive assessment for complex PS; whereas the preoperative identification of individualized drainage of the feeding vessels using a more practical tool such as 3D-CTA is essential for the safe performance of anatomic lung resection. Digital anatomy models established by 3D-CTA are therefore utilized to identify the variations of the PS, which can help definitely confirm the diagnosis, overcome technical challenges, and improve the safety with fluency [9-11].

Uniportal VATS has evolved dramatically into a sophisticated procedure capable of performing major complex lung resection [12]. A meta-analysis shows that the perioperative outcomes of uniportal and multiport VATS anatomic pulmonary resection are equivalent [13]. However, another systematic review showed that it remains premature to declare its superiority [14]. Due to the limited sample size of the present cohort study, the quantitative analysis might deliver misleading information. Thus, a literature review was performed. We searched PubMed, Web of Science, Scopus, Embase, Cochrane Library and Google Scholar for relevant English reports of VATS lung resection for PS up to September 24th, 2021 based on the population, intervention, comparator, outcome and strategy (PICOS) framework. Key words and MeSH terms in title or abstract including "Video-Assisted", "Thoracoscopic", "VATS", "Bronchopulmonary Sequestration", "PS", and "Pulmonary Sequestration" were used. The search strategy for PubMed was as follows: ((("Thoracic Surgery, Video-Assisted"[Mesh]) OR (Video-Assisted[Title])) OR (Thoracoscopic[Title])) OR (VATS[Title])) AND ((("Bronchopulmonary Sequestration"[Mesh]) OR (Bronchopulmonary Sequestration[Title])) OR (Pulmonary Sequestration[Title])) OR (Pulmonary Sequestrations[Title])). The selection of studies was based on the abstracts and full texts. Review, letters to the editor, comments, correspondence, case reports, surgical technique notes, meeting abstracts, unpublished studies with less than 5 patients, pediatrics with PS were excluded. Finally, a total of 13 retrospective cohort studies including 350 adolescent and adult patients (range of age, $14-76$ years) were reviewed (Table 3). 
Table 3

Previous reports of thoracoscopic lung surgery for adult patients with pulmonary sequestration

\begin{tabular}{|c|c|c|c|c|c|c|c|c|c|c|c|}
\hline $\begin{array}{l}\text { First } \\
\text { author, } \\
\text { year }\end{array}$ & $\begin{array}{l}\text { No. of } \\
\text { patients }\end{array}$ & Age, $y$ & $\begin{array}{l}\text { ILS/ELS, } \\
\text { n }\end{array}$ & $\begin{array}{l}\text { Location: } \\
\text { left/right } \\
\text { thorax, n }\end{array}$ & $\begin{array}{l}\text { Origin of } \\
\text { the feeding: } \\
\text { thoracic } \\
\text { /abdominal } \\
\text { aorta, } \mathrm{n}\end{array}$ & Procedure & $\begin{array}{l}\text { Conversion, } \\
\mathrm{n} \text { to } \\
\text { multiport or } \\
\text { thoracotomy }\end{array}$ & $\begin{array}{l}\text { Duration } \\
\text { of } \\
\text { operation, } \\
\text { min }\end{array}$ & $\begin{array}{l}\text { Estimated } \\
\text { bleeding, } \\
\text { mL }\end{array}$ & $\begin{array}{l}\text { Chest } \\
\text { tube } \\
\text { drainage } \\
\text { or } \\
\text { hospital } \\
\text { stay, d }\end{array}$ & $\begin{array}{l}\text { Major } \\
\text { compli }\end{array}$ \\
\hline $\begin{array}{l}\text { Kestenholz, } \\
2006 \text { [15] }\end{array}$ & 14 & $20-64$ & $13 / 1$ & $6 / 8$ & $\begin{array}{l}10 / 3 ; 1 \\
\text { from right } \\
\text { renal artery }\end{array}$ & MVATS & $1(7.1 \%)$ & $\begin{array}{l}133(45- \\
270)\end{array}$ & $\begin{array}{l}200(20- \\
1200)\end{array}$ & $\begin{array}{l}7.5(3- \\
13)\end{array}$ & $\begin{array}{l}3 \text { pneu } \\
\text { hemotl }\end{array}$ \\
\hline $\begin{array}{l}\text { Tsang, } \\
2006 \text { [16] }\end{array}$ & 6 & $27-64$ & $6 / 0$ & $4 / 2$ & $6 / 0$ & MVATS & 0 & $\begin{array}{l}112.8 \\
(90-140)\end{array}$ & $\begin{array}{l}283.3(100- \\
500)\end{array}$ & 3.2 & $\begin{array}{l}1 \text { wour } \\
\text { infectic }\end{array}$ \\
\hline $\begin{array}{l}\text { Shen, } 2013 \\
\text { [17] }\end{array}$ & 25 & $16-62$ & $25 / 0$ & $16 / 9$ & $\begin{array}{l}21 / 2 ; 1 \\
\text { phrenic } \\
\text { artery; } 1 \\
\text { intercostal } \\
\text { artery }\end{array}$ & MVATS & 0 & $\begin{array}{l}114.2 \pm \\
31.2\end{array}$ & $228 \pm 96.5$ & $3.2 \pm 1.4$ & 0 \\
\hline $\begin{array}{l}\text { Liu, } 2013 \\
\text { [4] }\end{array}$ & 18 & $15-61$ & $16 / 2$ & $14 / 4$ & $15 / 3$ & MVATS & 0 & $\begin{array}{l}133.1 \pm \\
42.3\end{array}$ & $\begin{array}{l}186.1 \pm \\
279.4\end{array}$ & $2.7 \pm 0.8$ & 1 pneu \\
\hline $\begin{array}{l}\operatorname{Lin}, 2016 \\
{[18]}\end{array}$ & 26 & $14-68$ & $26 / 0$ & $21 / 5$ & $\begin{array}{l}22 / 3 ; 1 \\
\text { celiac trunk }\end{array}$ & MVATS & 0 & $\begin{array}{l}115.0 \pm \\
30.4\end{array}$ & $\begin{array}{l}65.0 \pm \\
47.9\end{array}$ & $3.7 \pm 1.3$ & $\begin{array}{l}1 \text { blooc } \\
\text { sputun }\end{array}$ \\
\hline $\begin{array}{l}\text { Wang, } \\
2016 \text { [19] }\end{array}$ & 16 & $34.2 \pm 14.0$ & $16 / 0$ & $13 / 3$ & $14 / 2$ & MVATS & $3(18.8 \%)$ & $122 \pm 40$ & $116 \pm 90$ & $5.9 \pm 1.4$ & $\begin{array}{l}1 \text { intrac } \\
\text { leakag }\end{array}$ \\
\hline $\begin{array}{l}\operatorname{Lin}, 2018 \\
{[20]}\end{array}$ & 19 & $17-62$ & $17 / 2$ & $14 / 5$ & $17 / 2$ & $\begin{array}{l}\text { 7UVATS, } \\
\text { 12MVATS }\end{array}$ & 0 & $\begin{array}{l}(151.6 \pm \\
43.9) \text { vs. } \\
(173.5 \pm \\
63.1)\end{array}$ & $\begin{array}{l}(64.3 \pm \\
62.7) \text { vs. } \\
(87.5 \pm \\
102.5)\end{array}$ & $\begin{array}{l}(3.0 \pm \\
1.9) \mathrm{vs} . \\
(4.0 \pm \\
2.7)\end{array}$ & $\begin{array}{l}1 \text { air le: } \\
\text { chylott }\end{array}$ \\
\hline $\begin{array}{l}\mathrm{Li}, 2018 \\
{[21]}\end{array}$ & 42 & $42.6 \pm 11.5$ & $42 / 0$ & $32 / 10$ & $35 / 7$ & $\begin{array}{l}1-2 / 3-4 \\
\text { ports } \\
\text { VATS }\end{array}$ & $2(4.8 \%)$ & $154 \pm 52$ & $193 \pm 238$ & $3.9 \pm 1.5$ & $\begin{array}{l}1 \text { reope } \\
\text { transfu }\end{array}$ \\
\hline $\begin{array}{l}\text { Li, } 2019 \\
{[22]}\end{array}$ & 33 & $23-55$ & $33 / 0$ & $19 / 14$ & $\begin{array}{l}24 / 8 ; 1 \\
\text { intercostal } \\
\text { artery }\end{array}$ & $\begin{array}{l}\text { 19UVATS, } \\
\text { 14MVATS }\end{array}$ & 0 & $\begin{array}{l}(123.5 \pm \\
27.3) \text { vs. } \\
(128.4 \pm \\
18.5)\end{array}$ & $\begin{array}{l}100 \text { (70- } \\
150) \text { vs. } \\
145(120- \\
185)\end{array}$ & $\begin{array}{l}3(2-3) \\
\text { vs. } 3.5 \\
(3-4)\end{array}$ & $\begin{array}{l}4 \text { ches1 } \\
\text { cough/ } \\
\text { hemop }\end{array}$ \\
\hline $\begin{array}{l}\text { Wang } \\
2019 \text { [23] }\end{array}$ & 35 & $16-76$ & $29 / 6$ & $28 / 7$ & $\begin{array}{l}29 / 4 ; 1 \\
\text { subclavian } \\
\text { artery; } 1 \\
\text { other }\end{array}$ & MVATS & 0 & $\begin{array}{l}150(75- \\
300)\end{array}$ & $\begin{array}{l}50(10- \\
600)\end{array}$ & $3(1-10)$ & 1 hoars \\
\hline $\begin{array}{l}\mathrm{Li}, 2020 \\
{[24]}\end{array}$ & 67 & $15-71$ & $65 / 2$ & $48 / 19$ & $57 / 10$ & $\begin{array}{l}21 \\
\text { UVATS, } \\
46 \\
\text { MVATS }\end{array}$ & $6(9.0 \%)$ & $\begin{array}{l}126(95- \\
170)\end{array}$ & $\begin{array}{l}100(50- \\
150)\end{array}$ & $4.1 \pm 1.5$ & 5 (7.5\% \\
\hline $\begin{array}{l}\text { Sun, } 2020 \\
{[25]}\end{array}$ & 24 & $18-65$ & $21 / 3$ & $20 / 4$ & $\begin{array}{l}20 / 3 ; 1 \\
\text { other }\end{array}$ & UVATS & 0 & $\begin{array}{l}102(55- \\
150)\end{array}$ & $\begin{array}{l}90(10- \\
300)\end{array}$ & $4(1-10)$ & 1pneur \\
\hline $\begin{array}{l}\text { Bishnoi, } \\
2021 \text { [26] }\end{array}$ & 25 & $16-28$ & $25 / 0$ & $15 / 10$ & $\begin{array}{l}18 / 5 ; 2 \\
\text { others }\end{array}$ & NA & $1(4.0 \%)$ & 179 & 204 & 3 & $\begin{array}{l}1 \text { reopє } \\
\text { air leak }\end{array}$ \\
\hline Summary & 350 & $14-76$ & $\begin{array}{l}334 \\
(95.4 \%) / \\
16 \\
(4.6 \%)\end{array}$ & $\begin{array}{l}250 \\
(71.4 \%) / \\
100 \\
(28.6 \%)\end{array}$ & $\begin{array}{l}288 \\
(82.3 \%) / 52 \\
(14.9 \%) ; 10 \\
\text { others } \\
(2.8 \%)\end{array}$ & - & $13(3.7 \%)$ & $\begin{array}{l}\text { Mean, < } \\
180\end{array}$ & $\begin{array}{l}\text { Mean, < } \\
300\end{array}$ & $1-13$ & $26(7.4$ \\
\hline
\end{tabular}

ILS, intralobar pulmonary sequestration; ELS, extralobar pulmonary sequestration; LLL, left lower lobe; RLL, right lower lobe; UVATS, uniportal video-assisted thoracoscopic surgery; MVATS, multiport video-assisted thoracoscopic surgery; NA, not available.

These studies presented 334 (95.4\%) patients with intralobar PS and 16 (4.6\%) patients with extralobar PS; whereas 250 (71.4\%) and 100 (28.6\%) lesions were located in the left and right thorax, respectively. In addition, 288 (82.3\%) and 52 (14.9\%) patients revealed aberrant feeding artery originated from the thoracic and abdominal aorta, respectively; whereas the other $10(2.8 \%)$ showed feeding artery from the branches of the aorta including intercostal, phrenic, gastric artery. Nearly one-half of the adult PS patients presented asymptomatic. The overall proportion of conversion from uniportal or multiport VATS to thoracotomy was $3.7 \%$ (13/350). Moreover, the mean operation time was less than $180 \mathrm{~min}$, followed by an estimated intraoperative blood loss of less than $300 \mathrm{~mL}$ per patient. Major surgery-related complications such as respiratory tract infection, pneumothorax, chylothorax, and prolonged air leakage occurred in 26 ( $7.4 \%$ ) patients. In total, only one patient $(0.3 \%, 1 / 350)$ recorded reoperation for unknown reason. Furthermore, the postoperative chest tube duration was ranged from 1 to 13 days. The currently available evidence, although with low quality due to the limited sample size and their retrospective nature, proved the feasibility and safety of uniportal VATS anatomic lung resection for PS. As compared with the above literature, the patients in the uniportal group of our study reported no conversion to thoracotomy or major bleeding. Therefore, uniportal VATS with 3D-CTA could be recommended as the optimal surgical procedure for PS. 


\section{Conclusions}

The current evidence confirmed the safety and advantages of uniportal VATS lung resection assisted with 3D-CTA for PS. Multicenter studies with larger sample size are needed to validate these findings.

\section{Abbreviations}

PS, pulmonary sequestration; ILS, intralobar pulmonary sequestration; ELS, extralobar pulmonary sequestration; VATS, video-assisted thoracoscopic surgery; CT, computed tomography; 3D-CTA, three-dimensional computed tomography angiography; PICOS, population, intervention, comparator, outcome and strategy.

\section{Declarations}

\section{Ethics approval and consent to participate}

Informed consent of the operation was obtained from all patients before surgery. The data were presented anonymously for privacy concern. The ethical review and informed consent were obtained from the institutional Review Board and the Ethics Committee of Xuzhou Central Hospital.

\section{Consent for publication}

Written informed consent for publication was obtained from all participants.

\section{Availability of data and materials}

The datasets analyzed during the current study are available from the corresponding author on reasonable request. The data generated in the review are included in this published article.

\section{Competing interests}

The authors declare that they have no competing interests.

\section{Funding}

Not applicable.

\section{Authors' contributions}

WZ, MZ and WW wrote this paper. $\mathrm{HZ}$ and MZ contributed to the screening and selection of the reports from the databases. All authors contributed to preparation of the data used in this paper. All authors read and approved the final manuscript.

\section{Acknowledgements}

The authors would like to thank all the reviewers for their constructive advices.

\section{References}

1. Gabelloni M, Faggioni L, Accogli S, Aringhieri G, Neri E. Pulmonary sequestration: What the radiologist should know. Clinical imaging. 2021, 73:61-72.

2. Lin ZW, Xu ST, Wang Q. Uniportal video-assisted thoracic lobectomy in a semiprone position for the treatment of a large intralobar pulmonary sequestration. Interactive cardiovascular and thoracic surgery. 2015, 21(4):542-544.

3. Sihoe ADL, Luo Q, Shao G, Li Y, Li J, Pang D. Uniportal thoracoscopic lobectomy for intralobar pulmonary sequestration. Journal of cardiothoracic surgery. 2016, 11:27.

4. Liu C, Pu Q, Ma L, Mei J, Xiao Z, Liao H, Liu L. Video-assisted thoracic surgery for pulmonary sequestration compared with posterolateral thoracotomy. The Journal of thoracic and cardiovascular surgery. 2013, 146(3):557-561.

5. Trabalza Marinucci B, Maurizi G, Vanni C, et al. Surgical treatment of pulmonary sequestration in adults and children: long-term results. Interactive cardiovascular and thoracic surgery. 2020, 31(1):71-77.

6. Cherian SV, Kumar A, Ocazionez D, Estrada YMRM, Restrepo CS. Developmental lung anomalies in adults: A pictorial review. Respiratory medicine. $2019,155: 86-96$

7. Chakraborty RK, Modi P, Sharma S. Pulmonary Sequestration. In: StatPearls. edn. Treasure Island (FL); 2021.

8. Sha JM, Zhao H, Lin ZB. Anomalous Systemic Arterial Supply to the Lung: To Which Category Should This Belong? Heart, lung \& circulation. 2020, 29(9):1292-1300. 
9. Zhang M, Liu D, Wu W, Zhang H, Mao N. Preoperative 3D-CT bronchography and angiography facilitates single-direction uniportal thoracoscopic anatomic lobectomy. Annals of translational medicine. 2019, 7(20):526.

10. Murota M, Yamamoto $\mathrm{Y}$, Satoh $\mathrm{K}$, et al. An analysis of anatomical variations of the left pulmonary artery of the interlobar portion for lung resection by three-dimensional CT pulmonary angiography and thin-section images. Japanese journal of radiology. 2020, 38(12):1158-1168.

11. Nagashima T, Shimizu K, Ohtaki Y, et al. Analysis of variation in bronchovascular pattern of the right middle and lower lobes of the lung using threedimensional CT angiography and bronchography. General thoracic and cardiovascular surgery. 2017, 65(6):343-349.

12. Ng CS, Rocco G, Wong RH, Lau RW, Yu SC, Yim AP. Uniportal and single-incision video-assisted thoracic surgery: the state of the art. Interactive cardiovascular and thoracic surgery. 2014, 19(4):661-666.

13. Yan $\mathrm{Y}$, Huang Q, Han H, Zhang Y, Chen H. Uniportal versus multiportal video-assisted thoracoscopic anatomical resection for NSCLC: a meta-analysis. Journal of cardiothoracic surgery. 2020, 15(1):238.

14. Sihoe ADL. Uniportal Lung Cancer Surgery: State of the Evidence. The Annals of thoracic surgery. 2019, 107(3):962-972.

15. Kestenholz PB, Schneiter D, Hillinger S, Lardinois D, Weder W. Thoracoscopic treatment of pulmonary sequestration. European journal of cardio-thoracic surgery : official journal of the European Association for Cardio-thoracic Surgery. 2006, 29(5):815-818.

16. Tsang FH, Chung SS, Sihoe AD. Video-assisted thoracic surgery for bronchopulmonary sequestration. Interactive cardiovascular and thoracic surgery. 2006, 5(4):424-426.

17. Shen JF, Zhang XX, Li SB, et al. Complete video-assisted thoracoscopic surgery for pulmonary sequestration. Journal of thoracic disease. 2013, $5(1): 31-35$.

18. Lin ZW, Gu J, Xu ST, Ge D, Wang Q. Video-Assisted Thoracoscopic Surgery for Intralobar Pulmonary Sequestration: Wedge Resection Is Feasible in Limited Peripheral Lesions. The Thoracic and cardiovascular surgeon. 2016, 64(5):456-460.

19. Wang LM, Cao JL, Hu J. Video-assisted thoracic surgery for pulmonary sequestration: a safe alternative procedure. Journal of thoracic disease. 2016, $8(1): 31-36$.

20. Lin TH, Huang WL, Chang CC, et al. Uniportal video-assisted thoracoscopic surgery lobectomy and segmentectomy for pulmonary sequestration. Journal of thoracic disease. 2018, 10(6):3722-3728.

21. Li Q, Xie D, Sihoe A, et al. Video-assisted thoracic surgery is associated with better short-term outcomes than open thoracotomy in adult patients with intralobar pulmonary sequestration. Interactive cardiovascular and thoracic surgery. 2018, 26(2):284-287.

22. Li XK, Luo J, Wu WJ, et al. Effect of different therapeutic strategies on the clinical outcome of asymptomatic intralobar pulmonary sequestration. Interactive cardiovascular and thoracic surgery. 2019, 29(5):706-713.

23. Wang S, Li Y, Wang J. Video-Assisted Thoracoscopic Surgery for Pulmonary Sequestrations: Series of 35 Consecutive Patients in a Single Center. The Thoracic and cardiovascular surgeon. 2019, 67(1):73-78.

24. Li Z, Zhao Y, Hu X, He W, Zhao X. Is uni-portal video-assisted thoracic surgery a feasible approach for the surgical treatment of bronchopulmonary sequestration? Journal of thoracic disease. 2020, 12(3):414-421.

25. Sun Y, Shao F, Zhang Q, Wang Z. Feasibility investigation of uniportal video-assisted thoracoscopic anatomical lung resection for pulmonary sequestration. Journal of cardiothoracic surgery. 2020, 15(1):93.

26. Bishnoi S, Puri HV, Asaf BB, et al. Video-assisted thoracoscopic surgery: The preferred method to manage pulmonary sequestration. Journal of minimal access surgery. 2021. doi: 10.4103/jmas.JMAS_251_20. Online ahead of print.

\section{Figures}




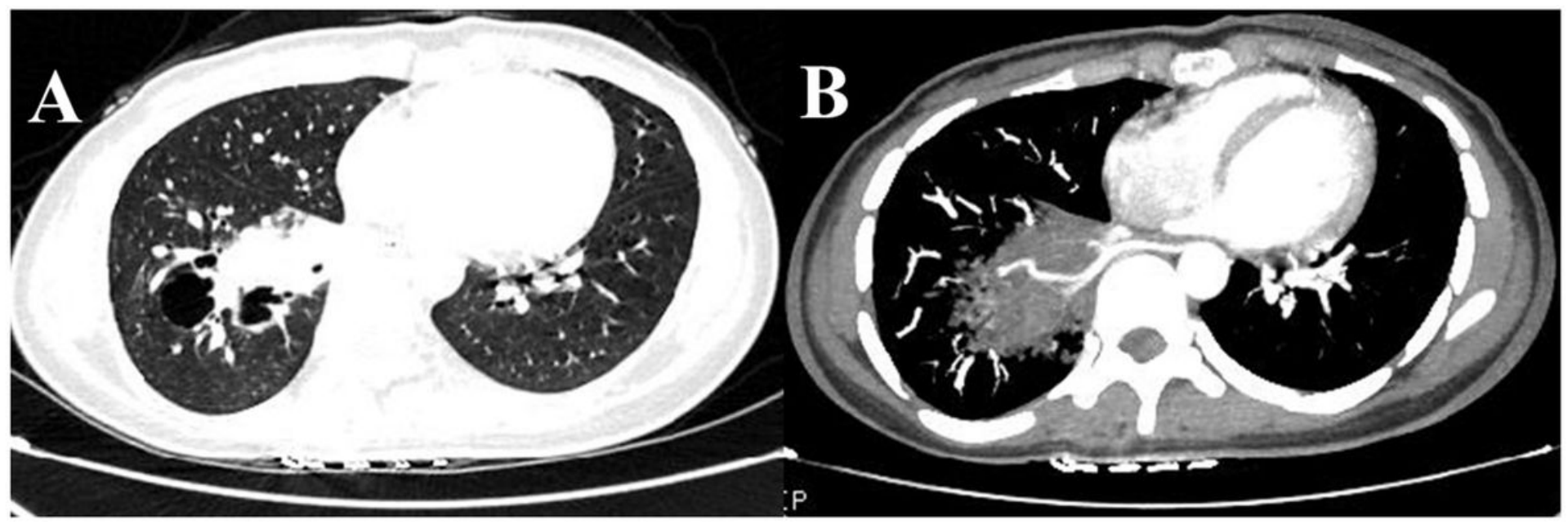

\section{Figure 1}

The sequestrated lung was located in the right lower lobe was diagnosed using conventional two-dimensional computed tomography. (A) The lesion mimics bronchiectasis and infection; (B) Contrast-enhanced images revealed the aberrant feeding vessel.

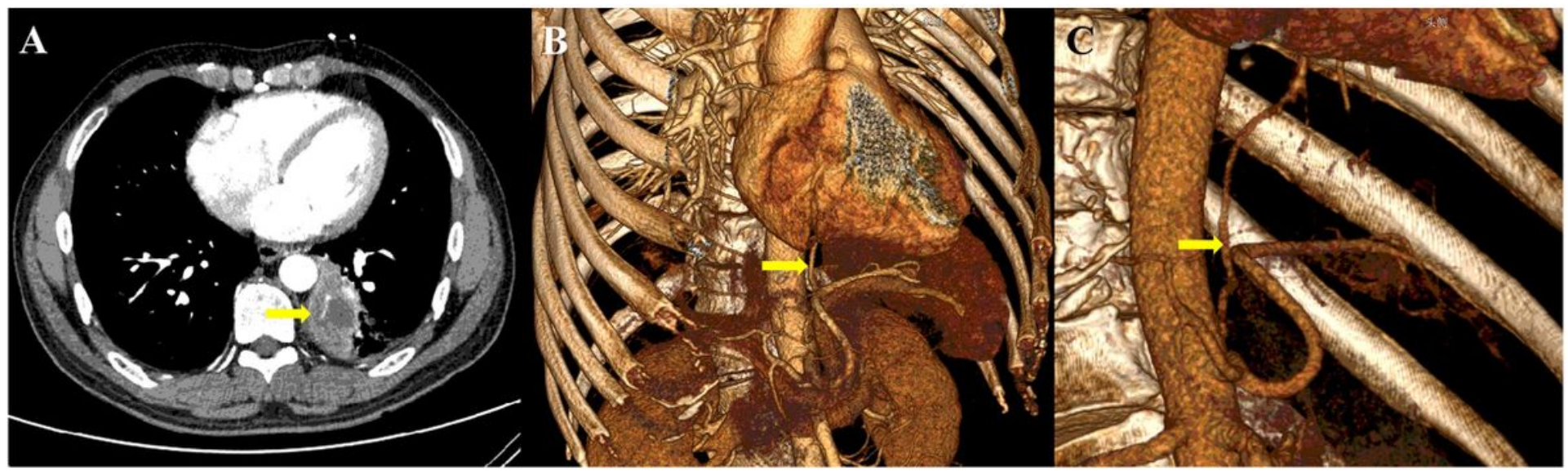

Figure 2

Three-dimensional computed tomography angiography showed definitely the anomalous blood supply. (A) A mass was located in the left lower lobe; (B) The abnormal feeding artery was next to the spleen artery; (C) The feeding artery originated from the abdominal aorta was finally confirmed. 